Doi: 10.22478/ufpb.1983-1579.2018v3n11.35501 http://periodicos.ufpb.br/ojs2/index.php

\title{
POLÍTICAS CURRICULARES EM EDUCAÇÃO AMBIENTAL NO CURSO DE PEDAGOGIA: um estudo de caso na Universidade Federal de Rondônia-UNIR
}

\section{CURRICULAR POLICIES IN ENVIRONMENTAL EDUCATION IN THE PEDAGOGY COURSE: a case study at the Federal University of Rondônia-UNIR}

\author{
Clarides Henrich de Barba ${ }^{1}$ \\ Elenice Cristina da Rocha Feza²
}

\begin{abstract}
Resumo: As Diretrizes Curriculares recomendam a inserção da temática ambiental nos currículos. Embora exista esta determinação, pesquisou-se se o emprego da mesma tem ocorrido no âmbito da prática educativa. Esta pesquisa apresenta o resultado de uma investigação sobre o desenvolvimento das ações docentes voltadas para a temática ambiental nos cursos de Pedagogia da Universidade Federal de Rondônia-UNIR, nos Câmpus de Porto Velho, GuajaráMirim e Ariquemes. O referencial teórico utilizado esteve baseado nos autores que abordam o currículo ambiental, e as políticas curriculares da educação ambiental Trata-se de uma pesquisa qualitativa, caracterizada como "estudo de caso". A metodologia adotada foi a qualitativa, um estudo de caso baseado em Stake (2009) tendo como instrumentos para a coleta de dados, a realização de entrevistas semiestruturadas com perguntas abertas a 7 (sete) professores das disciplinas dos Cursos de Pedagogia que trabalham com a temática ambiental. Os dados foram analisados com base na Análise de Conteúdo de Bardin (2011) que serviu para identificar e descrever as categorias relacionadas a temática ambiental nos Cursos de Pedagogia investigados. Os resultados apontam que os professores do curso de Pedagogia dos três câmpus trabalham com temas ambientais e que há um esforço em desenvolver um trabalho eficaz voltada para o ambiente físico e não para uma dimensão ambiental que envolva questões sociais, econômicas e culturais.
\end{abstract}

Palavras-Chave: Políticas Curriculares do Curso de Pedagogia. Educação Ambiental. Ensino Superior. Prática Docente.

\begin{abstract}
The Curricular Guidelines recommend insertion of the environmental theme in curricula. Although this determination exists, it was investigated whether the use of the same has occurred within the educational practice. This research presents the results of an investigation about the development of teaching activities focused on environmental issues in the courses of Pedagogy of the Federal University of Rondônia-UNIR, in the Campuses of Porto Velho, Guajará-Mirim and Ariquemes. The theoretical reference used was based on the authors that approach the environmental curriculum, and the curricular policies of the environmental education. This is a qualitative research, characterized as "case study". The methodology adopted was the qualitative one, a case study based on Stake (2009) having as instruments for the collection of data, the conduction of semi-structured interviews with open questions to 7 (seven) teachers of the courses of Pedagogy that work with the environmental themes. The data were analyzed based on the Content Analysis of Bardin (2011) that served to identify and describe the categories related to the environmental theme in the Courses of Pedagogy investigated. The results show that the teachers of the three-campus Pedagogy course work with environmental themes and that there is an effort to develop an effective work focused on the physical environment and not on an environmental dimension that involves social, economic and cultural issues.
\end{abstract}

Keywords: Curricular Policies of the Pedagogy Course. Environmental education. Higher education. Teaching Practice.

\footnotetext{
1 Professor Associado III do Departamento de Filosofia da Universidade Federal de Rondônia. E-mail: <clarides@unir.br>

${ }^{2}$ Mestre em Educação pela Universidade Federal de Rondônia - UNIR; Vice Diretora Faculdades Associadas de Ariquemes - FAAr. E-mail: <elenice@faar.edu.br>
} 


\section{INTRODUÇÃO}

A inserção da temática ambiental nos Cursos de Pedagogia pode ser analisada a partir da Resolução do Conselho Nacional de Educação/Conselho Pleno (CNE/CP) $n^{\circ} 1 / 2006$, que instituiu as Diretrizes Curriculares Nacionais para o Curso de Graduação de Licenciatura em Pedagogia que em seu artigo $2^{\circ}$, determinou a ampliação do campo da educação ambiental através de vários conhecimentos que podem ser discutidos teoricamente, bem como na prática.

Neste sentido, as universidades têm sido convocadas a trabalharem amplamente com os assuntos relacionados à temática ambiental no que diz respeito a formação de educadores. Este processo ressalta a importância de investigar os problemas ambientais na região amazônica, o que de fato apresenta as demandas para o enfrentamento dos graves acidentes ambientais, e que ressaltam a necessidade de intensificar os estudos sistemáticos sobre esta dimensão.

Após uma década da criação da Resolução do Conselho Nacional em relação aos cursos de Pedagogia no Brasil, pretende-se nesta investigação, apresentar os dados de uma pesquisa realizada nos anos de 2015/2016 em três Câmpus da Universidade Federal de Rondônia - UNIR, a saber: Ariquemes, Guajará-Mirim e Porto Velho com o objetivo de identificar o que tem sido desenvolvido na dimensão da Temática Ambiental no currículo e sua relação com a prática docente nos cursos de Pedagogia.

\section{DIRETRIZES CURRICULARES DO CURSO DE PEDAGOGIA E A TEMÁTICA AMBIENTAL}

A reformulação das Diretrizes do Curso de Pedagogia foi fruto de inúmeras discussões e interpretações, com disputas político-pedagógicas dos atores sociais nos diversos contextos sócio históricos e as várias identidades atribuídas ao curso de Pedagogia no Brasil, dentre as quais, cita-se a sua finalidade profissionalizante, como Licenciatura (SCHEIBE, 2007).

A Resolução nº 01 de 15 de maio de 2006 instituiu as Diretrizes Curriculares Nacionais (DCNS) para o Curso de Graduação de Licenciatura em Pedagogia. Assim, as políticas curriculares visam a construção do conhecimento escolar por meio de práticas educativas para que ocorram a reflexão e a ação crítica (LOPES, 2004; MACEDO, 2006).

No art. $2^{\circ}$ a Resolução destaca elementos epistemológicos da educação, entre eles, o ambientalecológico:

O curso de Pedagogia, por meio de estudos teórico-práticos, investigação e reflexão crítica, propiciará: I - o planejamento, execução e avaliação de atividades educativas; II - a aplicação ao campo da educação, de contribuições, entre outras, de conhecimentos como o filosófico, o histórico, o antropológico, o ambiental-ecológico, o psicológico, o linguístico, o sociológico, o político, o econômico, o cultural (BRASIL, 2006, p.11, grifo nosso).

As contribuições relacionadas ao campo ambiental podem definir políticas curriculares com a finalidade de planejar, executar e desenvolver ações educativas voltada à formação de professores nos cursos de Pedagogia.

Assim como o Art. $2^{\circ}$ destaca a importância do ambiental na formação do pedagogo, também o Art. $6^{\circ}$ das DCNs evidencia um núcleo voltado para a educação do trabalho e da sustentabilidade:

I - um núcleo de estudos básicos que, sem perder de vista a diversidade e a multiculturalidade da sociedade brasileira, por meio do estudo acurado da literatura pertinente e de realidades educacionais, assim como por meio de reflexão e ações críticas, articulará: [...] estudo das relações entre educação e trabalho, diversidade cultural, cidadania, sustentabilidade, entre outras problemáticas centrais da sociedade contemporânea (BRASIL,2006, p. 11, grifo nosso).

Estes elementos evidenciam que as DCNs de Pedagogia apresentam a diversidade cultural e o multiculturalismo como elementos necessários para compreender as questões sociais, econômicas, 
étnico-raciais e culturais que podem ser enfatizadas no exercício da docência, destacando a educação ambiental e ecológica.

Neste contexto, os DCNs também enfatizam o compromisso com a educação ambiental nos incisos X e XIV do Art. 6:

[...] X - demonstrar consciência da diversidade, respeitando as diferenças de natureza ambiental-ecológica, étnico-racial, de gêneros, faixas geracionais, classes sociais, religiões, necessidades especiais, escolhas sexuais, entre outras; $[\ldots]$

XIV - realizar pesquisas que proporcionem conhecimentos, entre outros: sobre alunos e alunas e a realidade sociocultural em que estes desenvolvem suas experiências não escolares; sobre processos de ensinar e de aprender, em diferentes meios ambiental- ecológicos; sobre propostas curriculares; e sobre organização do trabalho educativo e práticas pedagógicas [...] (BRASIL, 2006, p. 2, grifo nosso).

Os documentos oficiais para o curso de Pedagogia dizem respeito à importância da inserção da dimensão ambiental ainda durante a formação inicial que no âmbito da formação inicial de professores exigem uma ampla reflexão das práticas pedagógicas voltadas a formação de educadores ambientais (MORALES, 2009).

A inserção da temática ambiental no Ensino Superior consolida-se em 1991 quando o MEC, por meio da Portaria $n^{\circ} 678$, instituiu que todos os currículos nos diversos níveis de ensino deveriam contemplar conteúdos de EA por meio da interdisciplinaridade e transdisciplinaridade (SOTERO, SORRENTINO, 2010, OLIVEIRA, 2011).

Do mesmo modo, através da Lei $n^{\circ}$ 9.795/1999, em seu Art. $9^{\circ}$ instituiu a Política Nacional de Educação Ambiental (PNEA) e, por sua vez o Art. 10 determina a inclusão da dimensão ambiental nos currículos de formação de professores, em todos os níveis e em todas as disciplinas, tendo também que incorporar a temática ambiental (BRASIL, 1999).

É relevante demonstrar que entendemos a educação ambiental ser um processo na construção dos "valores sociais, conhecimentos e habilidades, atitudes e competências voltadas para conservação do meio ambiente, bem de uso comum do povo, essencial à sadia qualidade de vida e sua sustentabilidade" (BRASIL, 1999, p. 1).

Estes valores podem ser desenvolvidos pelos professores do Curso de Pedagogia por meio trabalho educativo em Educação ambiental de modo interdisciplinar.

Estas práticas pedagógicas nos Cursos de Pedagogia na região amazônica podem ser trabalhados por meio de um sentimento de pertencimento "nos aspectos que consideram importantes para a manutenção da vida, no modo como descrevem a Amazônia como algo sublime e, portanto, especial e que agrega um valor simbólico relevante para a sua cultura" (ANDRADE, 2014, p. 307).

Com a aprovação das Diretrizes Curriculares Nacionais para a Educação Ambiental, os valores podem ser evidenciados por meio dos compromissos de desenvolver os projetos institucionais e pedagógicos:

Art. 15. O compromisso da instituição educacional, o papel socioeducativo, ambiental, artístico, cultural e as questões de gênero, etnia, raça e diversidade que compõem as ações educativas, a organização e a gestão curricular são componentes integrantes dos projetos institucionais e pedagógicos da Educação Básica e da Educação Superior.

[...] $\S 3^{\circ}$ O tratamento pedagógico do currículo deve ser diversificado, permitindo reconhecer e valorizar a pluralidade e as diferenças individuais, 
sociais, étnicas e culturais dos estudantes, promovendo valores de cooperação, de relações solidárias e de respeito ao meio ambiente (BRASIL, 2012, p. 5).

As Diretrizes Curriculares da EA representam uma orientação normativa para todos os níveis e modalidades de ensino de modo que a sua inserção no currículo da Pedagogia pode orientar os conteúdos relacionados à Educação Ambiental com temas voltados aos valores do conhecimento, da ética e da política (CARVALHO, 2006).

A formação dos professores deve ser gradual possibilitando a superação da visão fragmentada da realidade social e da concepção do ser humano como acabado e imutável, pois o educador deve ser visto a partir de seus conhecimentos, representações e intencionalidades no que se refere a educação ambiental (MORALES, 2009).

Sorrentino et al. (2005, p. 292) considera que o processo formativo na Educação ambiental deve ter três eixos:

A formação desses educadores ambientais orienta-se por três eixos pedagógicos indissociáveis: a intervenção socioeducacional como práxis pedagógica, o estabelecimento de comunidades interpretativas e de aprendizagem e o acesso autogerido a cardápios de conteúdos e instrumentos pertinentes à problemática socioambiental de cada contexto.

Estes três eixos representam que a formação de professores é um processo relacionado entre a teoria e a prática, e que nos cursos de Pedagogia deve assumir relevância no projeto pedagógico dentro do sistema educativo, pois possibilita a reflexão crítica sobre as práticas educativas no exercício da docência na Educação ambiental, conforme pode ser observado na afirmativa de Carvalho (2001, p. 60):

Nesse sentido, os cursos de formação inicial dos professores desenvolvidos nas universidades poderiam investir em uma estrutura curricular muito mais flexível e dinâmica que facilitasse o tratamento das questões ambientais nos diferentes cursos de licenciatura por meio de experiências diversificadas e de uma abordagem que envolvesse os vários aspectos desse tema.

Estas ideias definem as políticas de formação nos cursos de licenciatura voltadas ao desenvolvimento do saber ambiental. A este respeito, a formação dos professores em IES, principalmente a nível curricular aponta que as soluções estão em fornecer ao educador uma formação em Educação ambiental nos cursos de pedagogia.

A inserção dos conteúdos ambientais no curso de Pedagogia devem estar voltados a temas como meio ambiente, a ética, a sustentabilidade que visam a construção do conhecimento na EA diante das diversas manifestações da vida voltado para a formação de professores nas relações entre homem, sociedade e natureza (TOMMASIELLO, ROCHA, 2013; GUERRA, FIGUEIREDO, 2014).

\section{DELINEAMENTO DA PESQUISA}

A metodologia adotada para essa pesquisa foi a qualitativa baseada no estudo de caso baseado em Stake (2009). Assim, em uma conjuntura do contexto educacional, o estudo de caso proporcionou condições de contemplar as possibilidades de novas alternativas diante da temática ambiental no Ensino Superior no curso de Pedagogia da Universidade Federal de Rondônia nos Câmpus de Porto Velho, Guajará-Mirim e Ariquemes.

Os procedimentos utilizados para a coleta de dados foram a análise de documentos por meio dos Projetos Político Pedagógico e realização de entrevistas semiestruturadas com perguntas abertas a 7 (sete) professores das disciplinas dos Cursos de Pedagogia que trabalham com a temática ambiental, com a seguinte descrição: Câmpus Porto Velho: P1; P2 E P3; Câmpus de Guajará-Mirim: P 4, P 5 e P 6, além do Câmpus de Ariquemes: P7.

Utilizou-se de um roteiro com perguntas abertas previamente organizadas para as entrevistas semiestruturadas com os coordenadores dos cursos e professores das disciplinas que trabalham a temática ambiental, as quais foram gravadas em áudio e posteriormente transcritas. 
Foram identificadas e descritas quatro categorias no currículo dos cursos de Pedagogia dos Câmpus da UNIR em Porto Velho, Guajará- Mirim e Ariquemes, a partir das respostas das entrevistas dos coordenadores e professores que trabalham com a temática ambiental considerando os objetivos e questões norteadoras do projeto de pesquisa, a saber: a). Temas abordados sobre a temática ambiental; b). Recursos didáticos e/ou metodologia utilizados na abordagem da temática ambiental; c) Ações acadêmicas institucionais - trabalhos que retratem os princípios e objetivos da Educação Ambiental; d) Contribuição da disciplina para a formação do futuro pedagogo.

A Análise de Conteúdo de Bardin (2011) serviu para identificar e descrever as categorias relacionadas a temática ambiental nos Cursos de Pedagogia que envolve três etapas primordiais, a saber, a pré-análise; a exploração do material; o tratamento dos resultados, a inferência e interpretação na organização dos dados.

\section{A TEMÁtICA AMBIENTAL E A PRÁtICA DOCENTE NO CURSO DE PEDAGOGIA DA UNIVERSIDADE FEDERAL DE RONDÔNIA: Câmpus de Porto Velho - Guajará Mirim e Ariquemes}

A temática ambiental que trabalhada na prática docente do curso de Pedagogia nos três câmpus investigados pode-se considerar quatro subcategorias a respeito da temática ambiental e a prática docente, a saber: a) Os Temas que são trabalhados em sala de aula sobre a temática ambiental: b) Recursos didáticos e/ou metodologia utilizados; c) Ações acadêmicas institucionais que retratem os princípios e objetivos da EA; d) Contribuição da disciplina para a formação do futuro pedagogo. Para responder estas subcategorias apresentaremos quatro quadros que estão relacionados aos depoimentos dos professores dos cursos de Pedagogia nos três câmpus investigados.

A primeira categoria evidenciada nas falas dos Professores dos cursos de Pedagogia da UNIR diz respeito aos Temas que são trabalhados em sala de aula sobre a temática ambiental:

Quadro 1 - SUBCATEGORIA: Temas abordados sobre a temática ambiental

\begin{tabular}{|c|}
\hline Câmpus Porto Velho \\
\hline 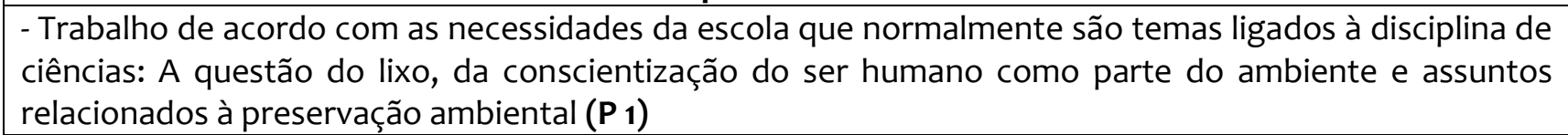 \\
\hline $\begin{array}{l}\text { - Trabalho a concepção ambiental, incluindo o desperdício da água, a gestão do lixo urbano e as } \\
\text { catástrofes ambientais (P 2) }\end{array}$ \\
\hline $\begin{array}{l}\text { - Temos uma série de questões importantes que não conseguimos lidar direito, como exemplo, a } \\
\text { relação de trabalho com o campo ainda é triste, no país a gente fala no trabalho escravo até hoje e esse } \\
\text { trabalho escravo se concentra no campo e não é só numa fazenda, mais em madeireiras, garimpos. } \\
\text { Então para mim qualquer forma de relação que o homem tenha com a natureza tem a ver com a } \\
\text { questão ambiental (P } \mathbf{3})\end{array}$ \\
\hline Câmpus Guajará-Mirim \\
\hline $\begin{array}{l}\text { - Trabalho muito no começo com a conscientização, por que nós não aprendemos a lidar com o lixo. No } \\
\text { entanto lixo não é lixo, é apenas um subproduto de tudo o que consumimos. O que descartamos para a } \\
\text { lixeira, naquele momento é lixo, mas se olhar para uma cadeia alimentar tem alguém que iria usar (P4) }\end{array}$ \\
\hline $\begin{array}{l}\text { - Se estou formando um acadêmico-professor para dar aula no ensino fundamental, ele precisa } \\
\text { conhecer a realidade do seu ambiente, conhecer a realidade do estado, como ele foi construído, } \\
\text { conhecer o processo de colonização, para depois tentar entender as questões legais baseadas no nosso } \\
\text { município, e como eu posso estar garantindo a formação do meu aluno o respeito desse ambiente, mas } \\
\text { acima de tudo, como utilizar esse ambiente ao seu favor, no meio em que ele vai viver (P 5) }\end{array}$ \\
\hline $\begin{array}{l}\text { - Que o aluno construa concepções de ambiente, não tendo o ambiente somente como um espaço } \\
\text { ecológico, não vendo somente ambiente como floresta, como rios, biodiversidades, mais vendo que a } \\
\text { temática ambiental envolve toda a relação do homem com o planeta, nos diversos lugares que ele } \\
\text { estiver no mais diversificado lugar que ele tiver, ele esta dentro do ambiente e é isso que eu procuro } \\
\text { (P6) }\end{array}$ \\
\hline
\end{tabular}




\section{Câmpus de Ariquemes}

- Trabalhei Educação Ambiental e Teorias e Práticas, a Educação Escolar a Forma de Organizar a Didática da Educação Ambiental e as Aplicações da Educação Ambiental em sala de aula, algumas diretrizes da Educação Ambiental e depois o desenvolvimento de projetos associados ao tema. Os temas e assuntos deveriam estar mais focados, trabalhados de uma forma mais precisa (P7)

Fonte: Coleta de Dados, 2016.

Analisando o Quadro 1 observa-se que dois professores do Câmpus de Porto Velho, (P1 e P2), consideram os temas trabalhados relacionados ao ambiente físico, a ecologia. Por outro lado, outro Professor ( $\left.\mathrm{P}_{3}\right)$ identifica que a sua maneira peculiar de trabalhar, é o de relacionar a natureza com as ações humanas.

Diante dos relatos, observa-se que a ênfase nos conteúdos da preservação ambiental, a cadeia alimentar, as questões com os resíduos sólidos, bem como nos temas voltados para a cidadania ambiental nas práticas de educação ambiental. Contudo, ao observar a temática ambiental no curso de Pedagogia da UFPA, Silva (2013, p. 30) afirma que os estudantes "em sua trajetória formativa indicou que a grande maioria percebe a EA como sendo de grande importância para sua formação e gostariam de vê-la nas práticas formativas do curso".

Observou-se que os temas ambientais devem ser inseridos no programa de ensino e debatidos em sala de aula, fundamento imprescindível para o desenvolvimento da prática em educação ambiental voltada para a formação, conforme demonstram os professores do Câmpus de Guajará Mirim. Assim, de acordo com o Professor ( $\mathrm{P} 4$ ) temas como o da sustentabilidade retratam a realidade cultural e como tal deve ser enfatizada na teoria e na prática, debatido na sala de aula.

A respeito da cultura e da sustentabilidade, Andrade e Gómez (2016, p. 41) afirmam

Sobre este tema, as e os docentes acreditam que por meio da Educação Ambiental é possível ampliar as oportunidades de fortalecer a participação social, com vistas a consolidar a cultura da sustentabilidade na Amazônia. Portanto, acreditam no poder das multitudes conscientizadas para o enfrentamento da problemática ambiental aí instalada.

Esta afirmativa reforça a tese proposta da necessidade dos cursos de formação de professores estejam relacionados com o contexto regional e cultural conforme destaca o Professor 5 em que se deve o conhecer os processos de colonização e as questões legais em que há uma preocupação com a formação do futuro profissional, daí a importância de entender todo o contexto ambiental na relação homem, sociedade e natureza.

Para um outro professor (P6), a construção do saber ambiental é um campo da ecologia, a qual ocorre nas relações do homem com a natureza e sociedade, mas que depende do ser humano respeitar e preservar. Assim, para a Professora ( $\mathrm{P} 7$ ) do Câmpus de Ariquemes explica que a temática ambiental pode ser trabalhada associada com várias áreas do conhecimento de modo mais direto, porém entende que o conhecimento não pode ser fragmentado.

Os temas ambientais que são apontados pelos professores dizem respeito aos problemas apontados pelos professores reforçam a questões trabalhadas por Fernside (2005) como a água, a biodiversidade, o lixo, a reciclagem, da habitat, da exploração de espécies, das queimadas na Amazônia, o que permite compreender a necessidade de termos um currículo ambientalizado com práticas educativas transformadoras.

Do mesmo modo, Azevedo, Higuchi e Barcelos (2009, p. 94) entendem que a Educação ambiental deve estar voltada para as problemáticas mais complexas na busca pela construção de uma cidadania, e como tal são necessários para serem trabalhos nas práticas educativas:

É notório que EA é, sobretudo, uma postura política de comprometimento e responsabilidade sócio-ambiental, uma vez que articula conhecimentos; propõe questões para serem debatidas e refletidas; constrói e promove intervenções processuais e até mesmo pontuais; chama atenção para o excessivo consumo 
de recursos naturais, enfim, ela contribui para que a sociedade repense seus modelos de produção, seus padrões de consumo e promove a ética do cuidado e respeito com seu semelhante e com outras formas de vida.

Para estes autores, a constituição sócio-ambiental na Amazônia apontam para um uso excessivo dos recursos naturais e que colocam o consumo em alta diante de padrões que estão fora do cuidado para com a vida e a preservação da biodiversidade. Estes elementos são fundamentais para que a Educação ambiental seja cada vez mais trabalhada no contexto amazônico, conforme afirmam Clement e Higuchi (2005, p. 49):

A educação ambiental é igualmente pobre. Se a Amazônia espera se desenvolver com base na floresta, como na visão que aqui se apresenta, o MEC e as secretarias estaduais de Educação precisam revisar as grades curriculares de primeiro grau à universidade para refletir a nova base da economia regional - atualmente a agricultura convencional é considerada a base da economia brasileira e permeia as grades curriculares.

Ao observar a Educação Ambiental voltada para uma educação do campo e também urbana identifica-se a necessidade do trabalho educativo presente no contexto regional, cultural e social. Estas condições devem ser enfatizados nos currículos dos cursos de licenciatura de professores e precisam "se ancorar no seguinte tripé: saber pensar, saber fazer e saber pensar o fazer. O pressuposto é o trabalho nas dimensões técnica, política e humana do ser professor/educador nos processos de formação" (AZEVEDO, HIGUCHI e BARCELOS, 2009, p. 94). Deste modo, a trilogia apontada por estes autores nos fazem refletir a importância do currículo ambiental, pois o saber técnico, reflexivo e político reforçam práticas educativas da Educação ambiental voltadas aos problemas ambientais da região Amazônia.

Na segunda subcategoria "Recursos Didáticos e metodológicos na abordagem da temática" aponta para dar suporte ao desenvolvimento do trabalho docente:

Quadro 2 - SUBCATEGORIA: Recursos didáticos e/ou metodologia utilizados na abordagem da temática ambiental

\section{Câmpus de Porto Velho}

- Fazemos oficinas, dentro da sala mesmo, no próprio horário de aula. Às vezes eu proponho uma oficina, faço circular a ideia de que eles têm que fazer o plano da oficina, precisa fazer um objetivo geral, especifico tudo aquilo que é normal discutir em didática, o pessoal do oitavo período do ano passado, trabalhou em ciências um bioma, eles não sabiam o que era eco sistema, chegaram à conclusão que no jardim você tem o eco sistema, às vezes numa floreira dependendo você tem o eco sistema, ao começar a discutir essas coisas foi para o currículo de ciência a gente começou a percebeu que os tópicos estavam todos lá, questão de animais e o que se quiser trabalhar a partir dali ( $\mathbf{P}_{1}$ )

- Primeiro precisa instrumentalizar o aluno, mostrando como são os fundamentos da questão ambiental histórica, é necessário ver à educação ambiental no currículo escolar, a Didática, pode ser utilizada para trabalhar essa questão ambiental e tem a prática que proporciona a eleição de temas. Geralmente utilizamos temas gerais para a discussão como poluição da água do solo, água do planeta, o desmatamento, esses são os temas maiores da Pedagogia, por que abrangem outros temas ( $\mathbf{P}$ 2)

- Faço questão de trabalhar com eles nessa disciplina, fazer com que eles visitem frequentes órgãos que tem haver com estas questões. Então eles vão até o IBAMA, SEDAM, SINE, INCRA, FUNAI, secretaria de agricultura e peço para que eles se apresentem e observem aquilo que eles produzem e o que não produzem, por que são órgãos que tem haver com essa ação direta do meio ambiente ( P 3$)_{3}$

Câmpus de Guajará Mirim 
- Uso aulas expositivas, filmes, aulas práticas, palavras cruzadas, desenhos, data show, pesquisa em sala de aula. Já trabalhei com duas turmas os conceitos principais da educação ambiental, e termino com o projeto e a aplicação da oficina, onde os grupos escolhem uma oficina e vão aplicar a mesma, tem sido muito bom trabalhar na teoria e na pratica, e ademais eles apresentam um relatório da percepção que tiveram (P4);

- Como sou da área tecnológica, gosto muito das filmagens, que eles filmem os espaços, os relatos, os trabalhos e também trabalho com a metodologia que é de mapas mentais, ou seja, fazer um mapeamento gráfico daquilo que se viu em campo (P 5 )

- Em 2012 no final da disciplina, os alunos fizeram um trabalho, eu dividi a turma em dois grupos e atribuí alguns temas. Os trabalhos apesar de terem focado muito o ecológico, me surpreendeu, pois eles desenvolveram com alunos de escolas do ensino fundamental e da educação infantil aqui do município, foram muito bons, um grupo fez numa chácara o outro grupo desenvolveu no ambiente da própria escola. Ampliaram a temática, apesar de questão ecológica ter prevalecido, eles dominaram o assunto e conseguiram ter a percepção de que não se pode focar somente para a questão ecológica (P 6).

\section{Câmpus de Ariquemes}

- Toda aula eu procurava trazer uma dinâmica ou uma atividade que estava associada com o conteúdo para eu poder desenvolver com eles, para eles perceberem também que eles poderiam levar para sala de aula nas séries iniciais. Então atividades assim lúdicas e simples para que eles pudessem associar o conteúdo e utilizar no dia a dia e depois na atividade profissional, então sempre procurei desenvolver diferentes atividades associadas ao conteúdo mesmo, juntando a teoria e a prática na execução dos projetos (P 7).

Fonte: Coleta de Dados, 2016.

Observa-se nestas falas que os professores trabalham com a Didática voltada ao ensino da temática ambiental, como a poluição, o desmatamento entre outros. Os Professores utilizam várias técnicas de ensino, como a visita aos órgãos ambientais, filmagens aos trabalhos com mapas mentais, leituras com autores da Educação Ambiental que discutem os valores do conhecimento, da ética, e da cidadania ambiental.

Em geral, os relatos dos professores demonstram que apesar das dificuldades encontradas na assimilação dos conteúdos relacionados à temática ambiental e a prática docente, os professores procuram inovar suas aulas para atender a demanda do assunto. Deste modo, remete-nos refletir a utilização dos instrumentos e procedimentos que facilitam a compreensão dos acadêmicos a respeito de determinado assunto ambiental, o que nos remente a compreender que o trabalho educativo dos docentes é fundamental para a realização de uma boa formação acadêmica, reforçados por Silva, Higuchi, Farias (2015, p. 1035):

Atividades educativas nesse contexto se situam no exercício responsável da cidadania, pois está relacionado com a identidade e pertencimento de uma coletividade. A formação cidadã pode contribuir para uma sociedade democrática, justa e ecologicamente sustentável, além de respeitar a diversidade biológica e sociocultural da vida. A proposta da educação ambiental não se limita apenas ao conhecimento sobre condições ambientais favoráveis. A dimensão subjetiva está presente nesse processo educativo, possibilitando o desenvolvimento da sensibilidade em reconhecer as necessidades individuais e coletivas.

Observou-se, assim, que os professores executam um trabalho substancial sobre a temática ambiental, propondo uma prática educativa com os estudantes, levando-os a sentirem-se partícipes do processo e corresponsáveis pela manutenção do meio ambiente. Há uma demonstração de interesse por parte dos acadêmicos e docentes na prática para realizar as atividades voltadas para a aprendizagem.

Em relação à utilização de recursos didáticos nas atividades docentes, Silva (2012) aponta que eles são importantes ferramentas para facilitar a aprendizagem e superar lacunas deixadas pelo ensino 
tradicional, e nesse caso, o cinema é um recurso bastante efetivo quando utilizado de modo crítico nos processos pedagógicos.

Ao discutir sobre a formação profissional docente, faz-se necessário considerar elementos que compõem essa formação, entre eles, pode-se destacar "o reconhecimento dos diversos saberes, a construção da autonomia, a práxis pedagógicas e, sobretudo, o compromisso social de cada profissional dentro de sua área de atuação" (CUNHA, 2012, p. 51).

A este respeito, a tese de Doutorado de Azevedo (2012, p. 90), ao se referir sobre esta participação dos jovens na comunidade de Juruti-PA, considerada como um processo de formação de jovens, reforça a busca da cidadania ambiental:

Em um dos casos mais interessantes relatados, o grupo de jovens da comunidade se organizou em grupos para fazer mutirão de coleta de lixo e passar nas casas das famílias para instruí-las sobre educação ambiental e os destinos mais apropriados de destinar o lixo.

Esta análise pode ser observada pelo fato de que as comunidades podem envolver-se com ações educativas ambientais, tanto no ensino formal e não formal.

Em se tratando das atividades acadêmicas, houve a necessidade de saber se os docentes entrevistados desenvolvem trabalhos que retratem os princípios e objetivos da Educação Ambiental e se como eles acontecem, conforme pode-se observar no Quadro 3:

Quadro 3-SUBCATEGORIA: Ações acadêmicas institucionais e trabalhos que retratem os princípios e objetivos da Educação Ambiental

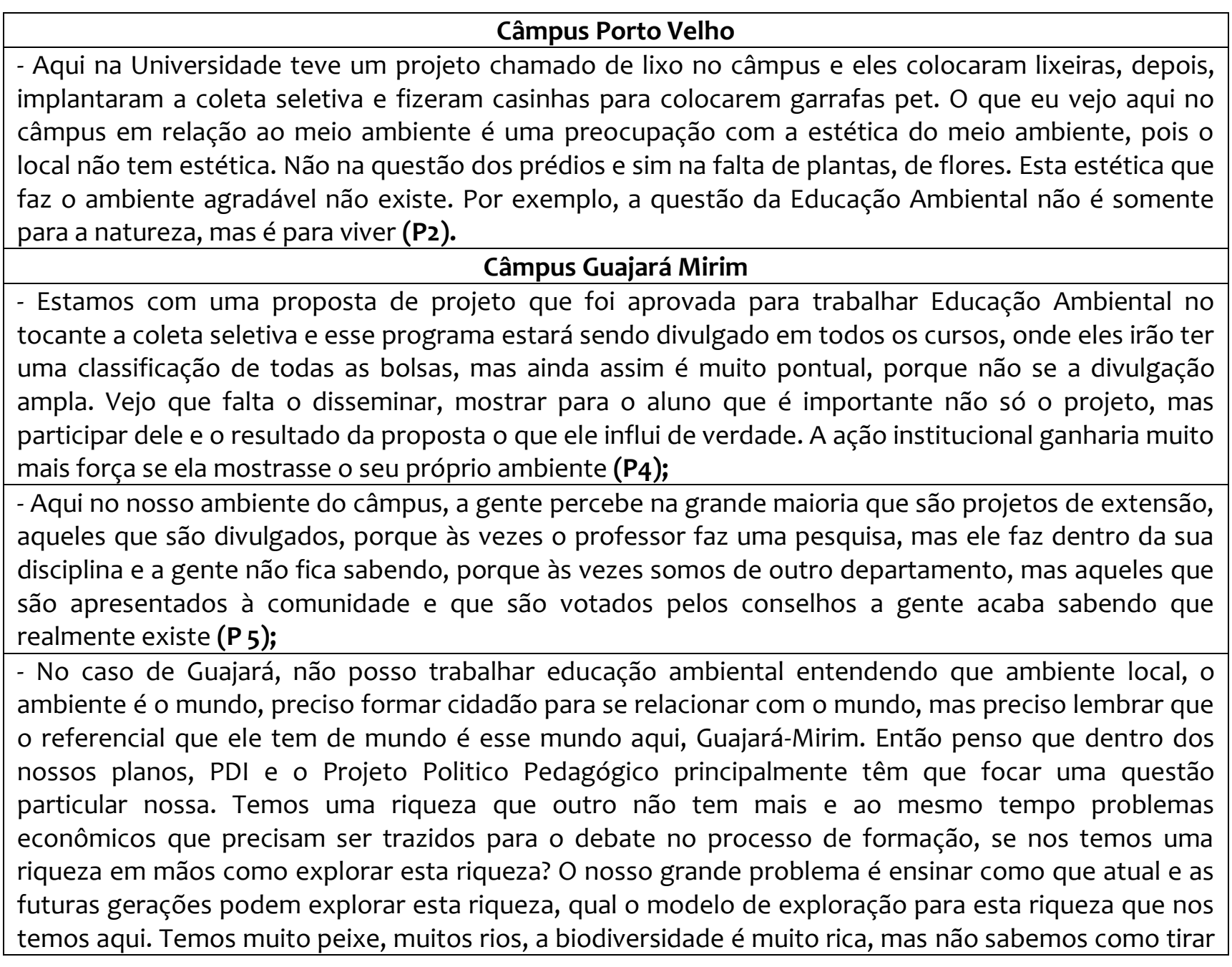


dai o produto pra garantir a qualidade de vida dessas pessoas, vivemos em sociedade e o homem precisa de emprego o de renda. (P6);

\section{Câmpus Ariquemes}

- Em 2009, a gente, em parceria com outra professora da Engenharia de Alimentos desenvolveu seis projetos com apoio da PROCEIA. Tínhamos seis bolsistas e conseguimos envolver um número aproximadamente de cem (100) acadêmicos aqui dentro da instituição em diversas ações voltadas pra área de Educação Ambiental. Então estes seis projetos tinham ações que visavam a Educação Ambiental. Vale lembrar que às vezes as pessoas associam a Educação Ambiental só a uma ou outra ação, por exemplo, nossos projetos era a elaboração de sabão a partir de óleo é que não estava sendo mais utilizado $(\mathrm{P} 7)$.

Fonte: Coleta de Dados, 2016.

No Câmpus de Porto Velho, a fala do P1 está relacionado com a determinação dessas ações nos documentos do curso, realizadas com o objetivo na formação do aluno. De acordo com os relatos dos professores deste Câmpus, pode-se verificar que de fato, quando se trata de ações voltadas para o meio ambiente, as mesmas são, na maioria dos casos, realizadas timidamente e/ou sem muita ênfase, vinculada a alguma disciplina e/ou professor, e consequentemente abriu a oportunidade para que toda a comunidade acadêmica e participe do empreendimento.

Dentro desta questão, o P3 limitou-se a informar que desconhecia o fato, ou seja, ele não sabia se havia proposta de trabalhos institucionais dentro da temática ambiental, o que nos remete a afirmação de Dias (1988, p. 130) em que "a aprendizagem será mais significativa se a atividade estiver adaptada concretamente às situações da vida real da cidade, ou do meio, do aluno e do professor".

Os professores do Câmpus de Guajará-Mirim (P4, P5 e P6) relatam que existem projetos desenvolvidos que envolvem a temática ambiental, e na maioria das vezes são realizados por meio do Departamento de Extensão. Neste aspecto, quando o professor executa as atividades por meio de projetos, as mesmas não são colocadas em evidencia como deveria e, portanto, não recebe a ênfase necessária. Esta mesma percepção ocorre no Curso de Pedagogia do Câmpus de Porto Velho, quando da realização de projetos, pois a falta de divulgação muitas vezes inviabiliza os mesmos e, portanto, não alcança o objetivo esperado.

Do mesmo modo, a narrativa da Professora do Câmpus de Ariquemes, (P7), a respeito dos projetos desenvolvidos no curso demonstra que existe uma lógica no desenvolvimento da reutilização do óleo para a confecção do sabão:

Então a gente ia para os restaurantes, dávamos um treinamento para o pessoal que trabalhavam neles e acabava focando um pouco com a Engenharia de Alimentos. Recolhia este óleo que produzia o sabão. Depois, doávamos o sabão para o abrigo das crianças e para o lar dos idosos ( $\mathrm{P} 7$ ).

Esta ação descreve a importância de que a produção do sabão é necessário para a realização do mesmo, enquanto prática educativa. Para esta professora é relevante desenvolver um trabalho educativo com os acadêmicos do curso de Pedagogia:

A educação não fica só voltada, no caso relatado acima, para reutilizar este óleo e produzir o sabão, e sim, para o fato social, de estar oferecendo um treinamento e contribuindo com um material ou outro para estas casas de apoio. Então é algo que vai bem além. Isso é bem interessante dentro da instituição que a gente tem este espaço e consegue desenvolver estes trabalhos. Além dos projetos citados anteriormente, tinha o projeto de Palestras, Teatro e Elaboração de Material Lúdico nas escolas sobre o Meio Ambiente. Todos os três projetos o número de acadêmicos de Pedagogia era bem maior e está mais associado assim na própria área deles $\left(\mathrm{P}_{7}\right)$.

A narrativa desta professora é um fator imprescindível para a formação de professores que deve ser identificada na teoria e na prática visando a participação em temas e em questões ambientais 
agregando valores que contribuem na formação dos futuros professores em Pedagogia no campo da cultura e da cidadania relacionado com a educação ambiental na Amazônia.

A este respeito, Dias (2001) considera que a Educação ambiental deve proporcionar uma visão crítica e autocrítica relacionados as realidades ecológicas, econômicas e sociais, políticas e culturais característicos dos problemas ambientais presentes na busca pela manutenção na qualidade sócioambiental. Neste aspecto, significa entender e compreender que tais elementos representem os significados dos caminhos percorridos pelos professores na construção e na formação de futuros educadores ambientais.

Considera-se, pois, a necessidade de gestores que promovam um ambiente participativo em contribuir voltado ao desenvolvimento de ações e práticas ambientais. Neste caso, evidencia-se que os temas ambientais podem ser uma oportunidade de exercer o pensamento crítico visando a aprendizagem. Buscou-se assim, conhecer de que modo a disciplina de Educação ambiental poderia contribuir na formação de futuros professores em Pedagogia, como demonstra o Quadro 4:

Quadro 4-SUBCATEGORIA: Contribuição da disciplina para a formação do futuro pedagogo

\begin{tabular}{|c|}
\hline Câmpus Porto Velho \\
\hline $\begin{array}{l}\text { - Eu tenho convicção disso, embora não tenha contato com todos eles quando estão na prática, } \\
\text { estamos pensando em fazer uma pesquisa com os egressos (P1) }\end{array}$ \\
\hline $\begin{array}{l}\text { - Contribuem, os relatos são muito bons. Por exemplo, hoje os alunos passam a prestar atenção no que } \\
\text { é dito, além de estarem aprendendo na escola, por meio do estágio. E essas práticas os fazem crescer (P } \\
\text { 2) }\end{array}$ \\
\hline 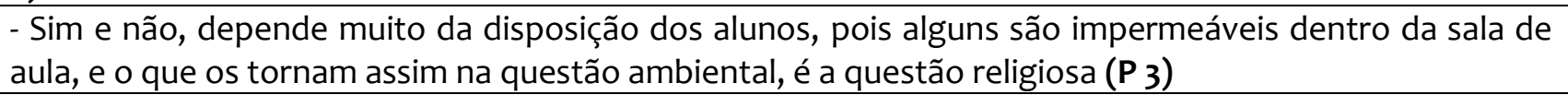 \\
\hline Câmpus Guajará Mirim \\
\hline $\begin{array}{l}\text { - Com certeza, principalmente da Educação Ambiental. Porque quando saírem da sala de aula, irão } \\
\text { influenciar outros é o que eu sempre digo. Como temos a Legislação que nos cobre para tratar desse } \\
\text { assunto periodicamente o professor que gosta vai buscar ensinar perfeitamente, já o que não se } \\
\text { importa não irá fazer muita questão (P4) }\end{array}$ \\
\hline $\begin{array}{l}\text { - Sim, como falei começa pelo pessoal, creio que muitos já entendem, porque tem aqueles que passam } \\
\text { sem entender nada no sentido de vida, continuam na universidade com a mesma postura do decorar e } \\
\text { memorizar do ensino médio, mas aqueles que conseguem compreender, eu creio que há uma mudança, } \\
\left.\text { eles levam para a sua vida para seu ambiente de trabalho ( } P_{5}\right)\end{array}$ \\
\hline Câmpus Ariquemes \\
\hline $\begin{array}{l}\text { - Para que o aluno consiga levar esta prática para dentro das escolas é outro caminho que a gente tem } \\
\text { que estar trabalhando, o trabalho de conscientização é um trabalho de insistência, vai se trabalhando } \\
\text { dia a dia, propondo atividades, são muitos conteúdos para quatro anos. Nós estamos no caminho, mas } \\
\text { não podemos nos dar por satisfeitos, precisamos ir, além disso. Posso dizer que existe, não uma } \\
\text { Ambientalização curricular, mas que isto esta em processo, existe uma iniciação, o curso de Pedagogia } \\
\text { mostra indícios de ambientalização curricular (P7) }\end{array}$ \\
\hline
\end{tabular}

Fonte: Coleta de Dados, 2016.

As falas demonstram que as contribuições da Educação ambiental seja um caminho possível para a formação de professores por meio de conteúdos interdisciplinares tralhados no decorrer do curso. Neste caso, quando um docente consegue envolver os estudantes com os recursos didáticos disponíveis é possível que o mesmo promova mudanças na formação de acadêmicos por meio do trabalho educativo que pode estar relacionado com o compromisso possível entre a sociedade e a natureza no que diz respeito aos valores da justiça, solidariedade e da equidade, aplicando os princípios éticos universalmente reconhecidos e o respeito às diversidades (JUNYENT; GELI, ARBAT, 2003).

Em relação a esta categoria e sua relação com a proposta da Rede ACES, observa-se a coerência e reconstrução entre teoria e prática por parte dos professores do curso de Pedagogia do Câmpus de 
Porto Velho de modo a desenvolver uma pluralidade metodológica visando a formação de uma consciência ambiental. Isso pode ser visto por meio dos discursos, na criação e recriação da dinâmica do conhecimento e das atividades práticas (BARBA, 2011).

Por meio dos depoimentos dos professores do Câmpus de Guajará Mirim, observou-se que existe um trabalho consciente para promover a formação acadêmica, e que depende dos mesmos em acompanhar as mudanças na dinâmica das novas gerações com a informação e o conhecimento de modo que as aulas sejam efetivamente produtivas e cumpram o seu objetivo de ensinar e de aprender.

Em seu trabalho a respeito das instituições de Ensino Superior do Amazonas, Cunha (2012) reforça que o excesso de discursos distantes da realidade pode proporcionar o empobrecimento das ações pedagógicas, pois se vive em um contexto em que todos podem saber precisamente o que fazer e como fazer nas questões relacionadas com a Educação ambiental.

As práticas educativas na Educação ambiental precisam criar mecanismos que possibilitem maiores atividades que incluam os acadêmicos e os façam sentir partícipes do meio, conforme pode ser observado no depoimento da professora:

Eu acredito que sim, porque, a gente inseriu alguns conteúdos para mostrar que não podemos ficar discutindo sempre os mesmos temas. A área ambiental é bem ampla, tem outras ações para serem desenvolvidas [...] No plano de curso da disciplina quando se fala em elaboração desenvolvimento e avaliação de projetos dentro da área de Educação Ambiental, foi um conteúdo importante, contribuiu muito para que eles adquirissem conhecimento, para o desenvolvimento destas atividades dentro da escola e facilitar para quando eles chegam no sexto e sétimo período para o TCC. Tem uma aluna que esta desenvolvendo a atividade no projeto de TCC na área de Meio Ambiente voltado para um parque, para um banco de sementes, eu estou orientando (P7).

A avaliação desta Professora remete que a avaliação dos conteúdos estão voltados para o desenvolvimento de atividades teóricas e práticas da EA voltadas para o saber ambiental:

O reconhecimento da necessidade de valorização da cultura local pode ter várias interpretações. Porém, não podemos negar que na Amazônia, secularmente, vislumbra-se um movimento contestatório que reivindica justiça ambiental e social. Este movimento, forjado contra o processo de invasão, apropriação e violência sobrevive nos dias atuais. Principalmente por meio da oralidade, tem demarcado territórios simbólicos em relação à cultura local. Possivelmente por esta razão, os protagonistas da pesquisa ressaltam que "devemos voltar às nossas raízes" (ANDRADE, 2014, p. 44, grifo no original).

Entende-se, assim, que o ensino necessita estar embasado nas práticas sociais e nas dinâmicas das diferentes culturas, valorizando os conhecimentos empíricos, o que pode acontecer por meio da coerência e reconstrução entre teoria e prática. Neste caso, a ideia de um multiculturalismo ambiental reflete as condições da cultura dos povos tradicionais, como os ribeirinhos, quilombas e indígenas, cujos conteúdos são trabalhados na disciplina de Educação ambiental nos cursos de Pedagogia nos Câmpus de Ariquemes, Guajará-Mirim e Porto Velho.

Constata-se, pois, por meio das análises das falas que a prática docente valorizam a peculiaridade regional e cultural dos cursos de Pedagogia analisados. Todavia o que se percebe nas falas dos professores vai além da interação entre as disciplinas, pois através dos projetos de extensão desenvolvidos, proporcionam um diálogo entre a teoria e a prática necessárias e complementares para a criação dinâmica do conhecimento, evidenciando assim, a característica da Rede ACES denominada de "Coerência e reconstrução entre teoria e prática". 
ISSN 1983-1579

Doi: 10.22478/ufpb.1983-1579.2018v3n11.35501

http://periodicos.ufpb.br/ojs2/index.php

\section{CONSIDERAÇÕES FINAIS}

Este trabalho esteve voltado a analisar as políticas públicas para Educação Ambiental cuja relevância estão presentes nas Diretrizes Curriculares do Curso de Pedagogia. Deste modo, investigouse a temática ambiental e a prática docente dos Professores que trabalham com a temática ambiental nos cursos de Pedagogia da Universidade Federal de Rondônia - UNIR, Câmpus de Porto Velho, Guajará - Mirim e Ariquemes. Ressalta-se, que a finalidade desta pesquisa foi conhecer como os professores investigados desenvolvem as práticas educativas da Educação Ambiental, como proposta de investigar as políticas públicas, bem como compreender como está se adequando diante da nova realidade.

Constatou-se que os cursos de Pedagogia podem trabalhar com a temática ambiental de forma transversal, contínua e permanente ao longo das disciplinas com a inclusão de conteúdos visando a formação de professores.

Por meio das entrevistas com os professores, foi possível constatar que há a preocupação em tratar dos assuntos relacionados ao tema e que trabalhos são realizados a fim de atender as propostas das disciplinas. Embora, entendam que precisam avançar e melhorar a prática pedagógica e os conhecimentos sobre o assunto que é tão complexo propiciar, primeiramente, o planejamento, execução e avaliação das atividades educativas e posteriormente, dentre outros conhecimentos, o ambiental ecológico, o econômico e o cultural. Entende-se, entretanto, que essa mentalidade é uma construção diária e que exigirá maior tempo para que haja a inserção do meio ambiente como um todo, nas discussões do ambiente escolar.

Percebeu-se que de modo geral, os professores estão inteirados com a Educação Ambiental e criam mecanismos para que ações pedagógicas possam ser efetivadas e os estudantes tenham uma formação mais consolidada dentro da temática.

Observou-se, ainda, que as práticas pedagógicas dos professores na Educação ambiental tem sido efetivada por meio da interdisciplinaridade, contudo a construção de projetos foi apontado como principal causa dessas dificuldades.

Os professores trabalham no sentido de atender as demandas exigidas pela temática ambiental voltada para o ambiente físico, além das questões sociais, econômicas e culturais. Embora, isto ocorra de maneira tímida e haja a necessidade de ampliar e consolidar as práticas pedagógicas dentro do contexto, proporcionando condições para que ocorram debates, desenvolvimento de projetos, aulas expositivas e/ou dialogadas, workshops, oficinas, entre outros, mais eficazes.

Do mesmo é necessário considerar que as políticas curriculares nos cursos de Pedagogia investigados possuem a responsabilidade de promover a formação dos profissionais da educação de maneira plena com a finalidade de formar um profissional apto para atender as demandas da Educação ambiental.

Portanto, por meio desta investigação pode-se dizer que o processo está ainda em construção, considerado um caminho em construção, e como tal exige inicialmente a adequação do currículo e das disciplinas voltadas para a Educação ambiental. Estes desafios representam acima de tudo que os professores e estudantes do meio universitário sejam capazes de adquirir capacidades de compreender e avaliar as inovações tecnológicas que possam contribuir para a efetivação do saber ambiental.

Do mesmo modo, a institucionalização da EA enquanto uma política curricular para o curso de Pedagogia nos remete ao processo de formação de professores voltada aos valores do conhecimento, aos valores da ética, da estética e da política em uma busca de compreensão da realidade social e cultural na Amazônia.

\section{REFERÊNCIAS}

ANDRADE, Francisca Marli Rodrigues. Educação Ambiental na Amazônia: um estudo com as representações sociais dos pedagogos, nas escolas da rede pública municipal de Castanhal-Pará (Brasil). 
Tese de doutoramento. Universidade de Santiago de Compostela (USC), Santiago de Compostela Espanha, 2014.

ANDRADE, Francisca Marli Rodrigues; GÓMEZ, José Antonio Caride. Educação Ambiental na Amazônia brasileira: participação e reclamos sociais em tempos pós-hegemônicos. Revista Espacios, 4/7, juliodiciembre 2016. Disponível em: <www.espaciostransnacionales.org >. Acesso em 03 jul. 2017.

AZEVEDO, Genoveva Chagas de, HIGUCHI, Maria Inês Gasparetto; BARCELOS Valdo. Contribuição do INPA na formação continuada de professores em educação ambiental: desafios, práticas e reflexões! Ambiente \& Educação, v. 14, 2009, p. 89-109.

AZEVEDO, Graziela. Conselhos Municipais Como Canal De Participação Pública: desafios para populações rurais na Amazônia. Um estudo de caso sobre Juruti-PA, 2012. 116 f. Dissertação (Mestrado em Administração Pública e Governo) - Escola de Administração de Empresas de São Paulo, 2012.

BARDIN, L. Análise de conteúdo. São Paulo: Edições 70, 2011.

BARBA, Clarides Henrich de. Ambientalização curricular no ensino superior: o caso da Universidade Federal de Rondônia - campus de Porto Velho, 2011, 310 f.; Tese (Doutorado em Educação Escolar) Universidade Estadual Paulista, Faculdade de Ciências e Letras, Campus de Araraquara. Acesso em: <http://repositorio.unesp.br> Acesso em 15 maio 2016.

BRASIL Lei n 9.795, de 27 de abril de 1999: dispõe sobre a educação ambiental, institui a Política Nacional de Educação Ambiental e dá outras providências. Brasília: Diário Oficial, 28 de abril de 1999. Disponível em: <http://www.planalto.gov.br/ccivil>. Acesso em 10 jun. 2016.

. Diretrizes Curriculares Nacionais para o Curso de Graduação em Pedagogia, licenciatura. Resolução $\overline{\mathrm{CNE} / \mathrm{CP}} \mathrm{n}^{\circ}$ 1, de 15 de mai. de 2006. Disponível em:http://portal.mec.gov.br/cne/arquivos/pdf/rcp01_06.pdf>. Acesso em acesso em 08 de ago. de 2016.

. Resolução $n^{\circ}$ 2, de 15 de junho de 2012. Estabelece as Diretrizes Curriculares Nacionais para a Educação Ambiental, 2012 Disponível em: <http://conferenciainfanto.mec.gov.br/images/pdf/diretrizes.pdf >. Acesso em 10 jun. 2016.

CARVALHO, Luiz Marcelo de. A Educação Ambiental e a formação de professores. In: BRASIL. SECRETARIA de Educação Fundamental. Coordenação-Geral de Educação Ambiental. Panorama da educação ambiental no ensino fundamental. Secretaria de Educação Fundamental - Brasília: MEC; SEF, 2001.

. A Temática Ambiental e o Processo Educativo: dimensões e abordagens. IN CINQUETTI, H Heloisa Chalmers Sisla; LOGAREZZI, Amadeo. Consumo e Resíduos: Fundamentos para o trabalho educativo. São Carlos, EdUFSCar, 2006, p. 19-41.

CLEMENT, Charles R.; HIGUCHI, Niro. A floresta amazônica e o futuro do Brasil. Ciência e Cultura, v. 58, n. 3, São Paulo, jul/set. 2006.

CUNHA, Valdenice Henrique. A dimensão ambiental e os currículos dos cursos de formação de professor nas Instituições de Ensino Superior em Manaus, 2012, 114 f. Dissertação (Mestrado em Sociedade e Cultura da Amazônia), Universidade Federal do Amazonas. Disponível em: <http://200.129.163.131:8080/handle/tede/2341> Acesso em 08 de ago. de 2016.

DIAS, Genebaldo Freire. Educação Ambiental: princípios e práticas. 5. ed., São Paulo: Global 1998.

A situação da Educação Ambiental no Brasil é fractal. In: BRASIL, MEC. Panorama da Educação Ambiental no Ensino Fundamental. Brasília: MEC; SEF, 2001.

FERNSIDE, Philip M. Desmatamento na Amazônia brasileira: História, índices e conseqüências. Megadiversidade, vol. 1, n. 4, p. 113-123, 2005.

GUERRA, Antonio Fernando Silveira; FIGUEIREDO, Maria Lúcia. Ambientalização curricular na Educação Superior: desafios e perspectivas. Educar em Revista, Curitiba, Editora UFPR, Edição Especial n. 3/2014, p. 109-126. 
ISSN $1983-1579$

Doi: 10.22478/ufpb.1983-1579.2018v3n11.35501

http://periodicos.ufpb.br/ojs2/index.php

JUNYENT, Mercé.; GELI, Anna Maria; ARBAT, Eva. Características de la ambientalización curricular: Modelo ACES. In: JUNYENT, Mercé; GELI, Anna Maria; ARBAT, Eva (Eds.). Ambientalización Curricular de los Estudios Superiores: Proceso de Caracterización de la Ambientalización Curricular de los Estudios Superiores. Girona: Universitat de Girona, Red ACES, 2003. v. 2, p. 15- 32.

LOPES, A. C. Políticas curriculares: continuidade ou mudança de rumos? Revista Brasileira de Educação, Rio de Janeiro, n. 26, p. 109-118, maio/ago.2004.

MACEDO, E. Currículo: política, cultura e poder. Currículos sem Fronteiras, v. 6, n. 2, p. 98-113, jul./dez. 2006.

MORALES, Angélica Góis Müller. A formação dos profissionais educadores ambientais e a universidade: trajetórias dos cursos de especialização no contexto brasileiro. Educar, Curitiba, n. 34, p. 185-199, 2009. Editora UFPR,

OLIVEIRA, Maria Gesualdo de. Cursos de Pedagogia em Universidades Federais Brasileiras: políticas públicas e processos de ambientalização curricular. 2011, 168f. Dissertação (Mestrado em Educação) Universidade Estadual Paulista Júlio de Mesquita Filho, Rio Claro, 2011.

SCHEIBE, Leda. Diretrizes Curriculares para os cursos de Pedagogia: trajetória longa e inconclusa. Cadernos de Pesquisa, v. 37, n. 130, jan./abr. 2007. Disponível em:

<http://www.scielo.br/pdf/\%oD/cp/v37n130/04.pdf> Acesso em: 08 de ago. de 2016.

SILVA, Maria Amparo dos Santos. Utilização de recursos didáticos no processo de ensino e aprendizagem de Ciências Naturais em turma de $8^{\circ}$ e $9^{\circ}$ anos de uma escola pública de Teresina no Piauí. In: VII CONNEPI, 7, Palmas. Anais do VII Connepi. Palmas: Instituto Federal do Tocantins: 2012.

SILVA, Marilena Loureiro da. A educação ambiental no ensino superior brasileiro: do panorama nacional às concepções de alunos (as) de pedagogia na Amazônia. Rev. Eletrônica Mestr. Educ. Ambient., v. especial, março de 2013, p. 18-33

SILVA, Winnie Gomes da; HIGUCHI, Maria Inês Gasparetto; FARIAS, Maria Solange Moreira de. Educação ambiental na formação psicossocial dos jovens Ciênc. Educ., Bauru, v. 21, n. 4, p. 1031-1047, 2015.

SORRENTINO, Marcos et al. Educação ambiental como política pública. Educação e Pesquisa, São Paulo, v. 31, n. 2, p. 285-299, maio/ago. 2005.

SOTERO, José Paulo. SORRENTINO, Marcos. A Educação Ambiental como Política Pública: Reflexões sobre seu Financiamento. Anais... V ENANPPAS GT, v. 6, 2010.

STAKE, Robert. A Arte de Investigação com Estudos de Caso. Porto: Fundação Calouste Gulbenkian, 2009.

TOMMASIELLO, Maria Guiomar C. ROCHA, Erilda M. P. D. Diretrizes curriculares nacionais para a educação ambiental: considerações sobre a sua implementação no Brasil. IX Congreso internacional sobre Investigación en Didáctica de Las Ciencias, Girona, 9-12 de septiembre de 2013, p. 684-688.

Recebido em: 21/06/2018

Aceito em: 11/09/2018 